Article

\title{
Bottom-up preparation of gold nanoparticle-mesoporous silica composite nanotubes as a catalyst for the reduction of 4-nitrophenol
}

\author{
Yongsheng Peng a,b, , Wenguang Leng b, ${ }^{b,}$, Bin Dong ${ }^{b}$, Rile Ge ${ }^{b}$, Hongdong Duan a,*, Yan'an Gao ${ }^{b, \#}$ \\ a School of Chemistry and Pharmaceutical Engineering, Qilu University of Technology, Jinan 250353, Shandong, China \\ ${ }^{\mathrm{b}}$ Dalian Institute of Chemical Physics, Chinese Academy of Sciences, Dalian 116023, Liaoning, China
}

A R T I C L E I N F O

Article history:

Received 7 January 2015

Accepted 7 February 2015

Published 20 July 2015

\section{Keywords:}

Gold

Mesoporous silica

Nanotube

Bottom-up approach

Catalyst

4-Nitrophenol reduction

\begin{abstract}
A B S T R A C T
Gold $(\mathrm{Au})$ nanoparticle (NP)-mesoporous silica $\left(\mathrm{SiO}_{2}\right)$ composite nanotubes were prepared by a bottom-up approach, in which Au NPs were anchored to the inner wall of mesoporous $\mathrm{SiO}_{2}$ tubular shells. In this composite, the agglomeration, exfoliation, and grain growth of Au NPs were restricted, and the loading and size of the catalyst NPs were easily tuned. The mesoporous shell, open ends, and one-dimensional passage of the $\mathrm{SiO}_{2}$ nanotubes all promote the diffusion of reactants, which enhanced the catalytic efficiency of this composite in the reduction of 4-nitrophenol. The $\mathrm{Au}$ NP-mesoporous $\mathrm{SiO}_{2}$ composite nanotubes also demonstrated good reusability, and no leaching or agglomeration of the Au NPs was observed during the catalytic reaction.
\end{abstract}

(C) 2015, Dalian Institute of Chemical Physics, Chinese Academy of Sciences. Published by Elsevier B.V. All rights reserved.

\section{Introduction}

Noble metal nanoparticles (NMNPs) composed of metals, such as $\mathrm{Au}, \mathrm{Ag}, \mathrm{Pt}$, and $\mathrm{Pd}$, that range in size from several to dozens of nanometers are effective heterogeneous catalysts for various chemical reactions, including degradation of organic molecules [1-5], oxidation [6,7], hydrogenation [8], and C-C coupling $[9,10]$. Because bare NMNPs tend to aggregate, which decreases their catalytic activity, supportive platforms are usually required to load, stabilize, and separate these nanocatalysts. Recently, carbon materials like activated carbon, carbon nanotubes, and graphene have been frequently used as supports because of their high specific surface area, mechanical strength, and chemical stability [11-14]. The exfoliation and grain growth of loaded NMNPs, and the poor control of their dispersity are urgent issues that need to be resolved. Mesoporous silica $\left(\mathrm{mSiO}_{2}\right)$ materials can also host NMNPs inside their periodic, size-fixed channels. For example, NMNPs have been generated in situ within the pores of MCM- 41 and SBA-15 by strategies such as chemical vapor deposition [15], supercritical fluids [16], impregnation [17], and ion exchange [18]. Although the exfoliation and grain growth of NMNPs can be substantially confined in $\mathrm{mSiO}_{2}$, other crucial parameters including size, morphology, and loading of nanocatalyst are still difficult to control.

Bottom-up strategies developed in recent years may help to overcome these limitations [19-22]. For example, the surface of polymer latex and silica colloidal nanospheres can be decorat-

\footnotetext{
* Corresponding author. Tel/Fax: +86-531-89631215; E-mail: hdduan67@gmail.com

\# Corresponding author. Tel/Fax: +86-411-84379992; E-mail: ygao@dicp.ac.cn

+ These authors contributed equally to this work.

This work was supported by the National Natural Science Foundation of China (21273235, 21303076, and 21403214) and the 100 Talents Program of the Chinese Academy of Sciences.

DOI: 10.1016/S1872-2067(14)60310-7 | http://www.sciencedirect.com/science/journal/18722067 | Chin. J. Catal., Vol. 36, No. 7, July 2015
} 
ed with certain functional moieties like amino or thiol groups. As a result, NMNPs capped with suitable modifiers may attach onto these core templates through coordination or electrostatic interactions. Coverage of such complex by an $\mathrm{mSiO}_{2}$ shell using sol-gel methodology would produce sandwich-like "coreNMNP-shell" structures. The advantages of such design are obvious: (1) NMNPs with determined composition, size, and morphology can be produced; (2) the loading of the nanocatalyst can be tuned simply by changing the concentration of their corresponding dispersion; (3) the agglomeration, exfoliation, and grain growth of NMNPs can be largely restricted because they are sandwiched between the core and shell; (4) reactants are easily transported across the $\mathrm{mSiO}_{2}$ shell to react with the internal NMNP catalysts.

Compared with a spherical $\mathrm{mSiO}_{2}$ shell, $\mathrm{mSiO}_{2}$ nanotubes with open ends and a one-dimensional passage are thought to allow more efficient reactant transportation. Unfortunately, because of the lack of readily dispersible nanowire templates, the bottom-up fabrication of $\mathrm{mSiO}_{2}$ nanotubes loaded with NMNPs is still challenging. Recently, the synthesis of aniline oligomer-based organic nanowires (ONWs) by self-assembly was reported [23]. Their unique water dispersity and surface charge means that these ONWs may be used as templates for the facile production of $\mathrm{NMNP}-\mathrm{mSiO}_{2}$ composite nanotubes. Herein, gold ( $\mathrm{Au}$ ) nanoparticles (NPs) are anchored to the inner wall of $\mathrm{mSiO}_{2}$ nanotubes. The catalytic performance of these $\mathrm{Au}-\mathrm{mSiO}_{2}$ composite nanotubes is also examined by their ability to reduce the representative organic dye 4-nitrophenol (4-NP).

\section{Experimental}

\subsection{Materials}

Poly(diallyldimethylammonium chloride) (PDDA, 20\% aqueous solution) was purchased from Sigma-Aldrich Poly(vinylpyrrolidone) (PVP, molecular mass $=58000 \mathrm{~g} / \mathrm{mol}$ ), ammonium persulfate (APS, 98.5\%), and trimethoxy(octadecyl)silane ( $\mathrm{C}_{18} \mathrm{TMS}$, 90\%) were obtained from Aladdin Reagent Co. Aniline, xylene, hydrogen tetrachloroaurate $\left(\mathrm{HAuCl}_{4}\right)$, trisodium citrate ( $\mathrm{Na}_{3} \mathrm{Cit}$ ), $\mathrm{NaBH}_{4}$, tetraethyl orthosilicate (TEOS), ammonia (28\%), and 4-NP were purchased from Sinopharm Chemical Reagent Co. Deionized water was used throughout the experiments.

\subsection{Synthesis of PDDA-modified ONWS}

Water-dispersible ONWs were synthesized according to the literature [23]. In a typical experiment, PVP (0.5 g) and APS (0.1 g) were dissolved in deionized water ( $50 \mathrm{~g}$ ). The solution was covered with xylene ( $20 \mathrm{~g}$ ) to construct an oil-water interface. Aniline $(0.1 \mathrm{~g})$ was added dropwise into the upper xylene phase, and then the system was left undisturbed at room temperature for $24 \mathrm{~h}$. ONWs formed in the bottom aqueous phase. The ONWs were separated by centrifugation and rinsed with deionized water.

The ONWs were modified with PDDA as follows. ONW powder (90 mg) and PDDA solution (1.0 g) were added to deionized water $(20 \mathrm{~g})$ and stirred at room temperature for 10 min. The PDDA-modified ONWs were separated by centrifugation and rinsed with deionized water three times before further usage.

\subsection{Synthesis of ONW-Au composites}

$\mathrm{Au}$ NPs (diameter $=12 \mathrm{~nm}$ ) were synthesized by a reported method [24]. An aqueous solution of $\mathrm{HAuCl}_{4}(5 \mathrm{~mL}, 3 \mathrm{mmol} / \mathrm{L})$ was mixed with deionized water $(10 \mathrm{~mL})$ and heated to boiling point. $\mathrm{Na}_{3} \mathrm{Cit}$ solution $(10 \mathrm{~mL}, 5 \mathrm{mmol} / \mathrm{L})$ was added, and then the mixture was reacted for $30 \mathrm{~min}$ to form a violet-red solution. Au NPs (diameter $=5 \mathrm{~nm}$ ) were synthesized using a similar procedure [25]. An aqueous solution of $\mathrm{HAuCl}_{4}(5 \mathrm{~mL}, 3$ $\mathrm{mmol} / \mathrm{L})$, deionized water $(25 \mathrm{~mL})$, and $\mathrm{Na}_{3} \mathrm{Cit}$ solution $(10 \mathrm{~mL}$, $5 \mathrm{mmol} / \mathrm{L})$ was mixed at room temperature. $\mathrm{NaBH}_{4}$ solution (10 mL, $2 \mathrm{mmol} / \mathrm{L}$ ) was added dropwise under vigorous stirring, giving a pale red solution after $30 \mathrm{~min}$.

To synthesize ONW-Au composites, a solution of Au NPs (12 $\mathrm{nm}, 1 \mathrm{~mL}$ ) was slowly injected into a solution of the PDDAmodified ONWs (90 mg) in water (20 g). The mixture was stirred for $20 \mathrm{~min}$ before centrifugation and rinsing with water. $\mathrm{Au}$ NPs with a diameter of $5 \mathrm{~nm}$ were attached onto the PDDA-modified ONWs in the same manner. The loading of $\mathrm{Au}$ NPs can be tuned by varying the volume of their solution mixed with ONWs.

\subsection{Synthesis of ONW-Au-SiO 2 composites}

ONW-Au composite (90 mg) was added to deionized water (20 g), ammonia (0.3 g), and ethanol (2.0 g). TEOS (0.3 g) and C18TMS (0.1 g) were added, and the mixture was stirred at room temperature for $12 \mathrm{~h}$. The product was isolated by centrifugation, rinsed with deionized water and then ethanol, and dried at $80{ }^{\circ} \mathrm{C}$ to give an $\mathrm{ONW}-\mathrm{Au}-\mathrm{SiO}_{2}$ composite as a pale yellow powder.

\subsection{Synthesis of $\mathrm{Au}-\mathrm{MSiO}_{2}$ composite nanotubes}

$\mathrm{ONW}-\mathrm{Au}-\mathrm{SiO}_{2}$ composite was heated at a rate of $2{ }^{\circ} \mathrm{C} / \mathrm{min}$ to $550{ }^{\circ} \mathrm{C}$ and then maintained at this temperature for $2 \mathrm{~h}$. During heating, both the ONWs and pore-directing agents (the alkyl chain of $\mathrm{C}_{18} \mathrm{TMS}$ ) within the $\mathrm{SiO}_{2}$ shell were removed to generate $\mathrm{Au}-\mathrm{mSiO}_{2}$ composite nanotubes as a pink powder. The $\mathrm{Au}-\mathrm{mSiO}_{2}$ composite nanotubes contained approximately $4 \%$ $\mathrm{Au}$ NPs when $1 \mathrm{~mL}$ of the 12-nm Au NP solution was used, as measured by inductively coupled plasma (ICP) spectroscopy. For comparison of catalytic performance, an analogue of the $\mathrm{Au}-\mathrm{mSiO}_{2}$ composite nanotubes was also prepared without using the pore-directing agent $\mathrm{C}_{18} \mathrm{TMS}$. This analogue is denoted as $\mathrm{Au}-\mathrm{SiO}_{2}$ composite nanotubes.

\subsection{Reduction of 4-NP}

The reduction of 4-NP by $\mathrm{NaBH}_{4}$ using $\mathrm{Au}-\mathrm{mSiO}_{2}$ composite nanotubes as a catalyst was performed in a quartz cuvette at 
room temperature. Typically, 4-NP aqueous solution $(0.1 \mathrm{~mL}, 5$ mmol/L) was mixed with an excess amount of fresh $\mathrm{NaBH}_{4}$ solution ( $1 \mathrm{~mL}, 0.2 \mathrm{~mol} / \mathrm{L}$ ), and then diluted to $4 \mathrm{~mL}$. Au- $\mathrm{mSiO}_{2}$ composite nanotubes $(0.1 \mathrm{~mL}, 1 \mathrm{mg} / \mathrm{mL})$ were added. The mixture was immediately subjected to ultraviolet-visible (UV-Vis) measurements as the first run (denoted as the starting point $t=0$ ). The absorption of the dispersion was tested at intervals of $3 \mathrm{~min}$ until the dye was completely reduced. As control experiments, $\mathrm{Au}-\mathrm{SiO}_{2}$ composite nanotubes and bare $\mathrm{Au}$ NPs were also used as catalysts in the reduction of 4-NP.

\subsection{Characterization}

The zeta potential of the samples was measured by a zeta potential analyzer (Nano-ZS90, Malvern, UK). The morphology of samples was observed by a transmission electron microscope (TEM, Tecnai G2 F30, FEI) operating at $120 \mathrm{kV}$, as well as a scanning electron microscope (SEM, QUANTA 200 FEG, the Netherlands) equipped with a cold-field emission gun operating at $20 \mathrm{kV}$. Fourier-transform infrared (FTIR) measurements were carried out on an FTIR spectrophotometer (TENSOR27, Bruker) in the range of $4000-400 \mathrm{~cm}^{-1}$ with powder-pressed KBr pellets. Thermogravimetric analysis (TGA, STA449F3, Netzsch, Germany) was performed from room temperature to 750 ${ }^{\circ} \mathrm{C}$ at a heating rate of $10{ }^{\circ} \mathrm{C} / \mathrm{min}$ and $\mathrm{N}_{2}$ flow rate of 20 $\mathrm{mL} / \mathrm{min}$. UV-Vis spectra were collected in the 200-600 nm range using a spectrophotometer (UV-2550, Shimadzu). Powder X-ray diffraction (XRD) patterns were measured on a diffractometer (RINT D/Max 2500, Rigaku) using $\mathrm{Cu} K_{\alpha}$ radiation $(\lambda=0.15432 \mathrm{~nm})$. The nitrogen physisorption experiment was performed on a gas sorption system (QUADRASORB SI, Quantachrome Instruments) using a dried powder sample that was degassed at $120{ }^{\circ} \mathrm{C}$ under vacuum. Pore size distribution curves were calculated from the desorption isotherm curves using the Barrett-Joyner-Halenda (BJH) method. The Au loading of the catalysts was determined by ICP on a spectrometer (ICPS-8100, Shimadzu) after dissolution in dilute $\mathrm{HF} / \mathrm{HCl}$ solution.

\section{Results and discussion}

\subsection{Synthesis of Au-mSiO 2 composite nanotubes}

The procedure used to produce $\mathrm{Au}-\mathrm{mSiO}_{2}$ composite nanotubes is illustrated in Scheme 1. First, negatively charged ONWs with a zeta potential of $-10 \mathrm{mV}$ were adsorbed by cationic polyelectrolyte PDDA to acquire a positively charged surface

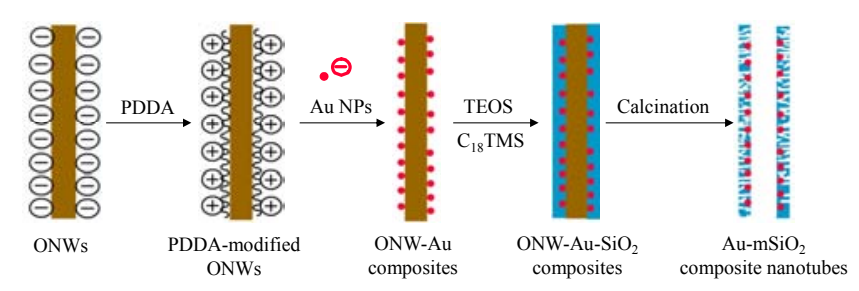

Scheme 1. Synthetic procedure to form $\mathrm{Au}-\mathrm{mSiO}_{2}$ composite nanotubes. with a zeta potential of $+60 \mathrm{mV}$. As a result, when the solution of citrate-stabilized Au NPs with a zeta potential of $-30 \mathrm{mV}$ was added, Au NPs spontaneously attached onto the PDDA-modified ONWs through electrostatic interactions to form the intermediate termed ONW-Au composite. The dispersion of ONW-Au composite was adjusted to $\mathrm{pH}=9-10$ before suitable amounts of TEOS and pore-directing agent $\mathrm{C}_{18}$ TMS were added to undergo a sol-gel reaction. Positively charged PDDA adsorbed on the surface of the ONWs interacted with the negatively charged silica sol-gel through electrostatic interactions, producing $\mathrm{a} \mathrm{SiO}_{2}$ shell on the surface of the ONW-Au composite to generate the $\mathrm{ONW}-\mathrm{Au}-\mathrm{SiO}_{2}$ composite. The thickness of the $\mathrm{SiO}_{2}$ coating could be controlled by varying the amount of precursors added. Because the Au NPs were sandwiched between the inner $\mathrm{ONW}$ template and outer $\mathrm{SiO}_{2}$ shell, their agglomeration, exfoliation, and grain growth should be restricted during calcination post-treatment. Calcination removed both the ONW template and pore-directing agents within the $\mathrm{SiO}_{2}$ shell to form $\mathrm{Au}-\mathrm{mSiO}_{2}$ composite nanotubes, in which $\mathrm{Au}$ NPs were anchored to the inner wall of an $\mathrm{mSiO}_{2}$ shell.

Fig. 1 shows TEM and SEM images of the intermediates and final product. The PDDA-modified ONWs were about $250 \mathrm{~nm}$ in diameter with a smooth surface (Fig. 1(a)). Well-dispersed $\mathrm{Au}$ NPs with a size of $12 \mathrm{~nm}$ (Fig. 1(b)) were then uniformly adsorbed onto the oppositely charged ONW templates (Fig. 1(c)). After coating with a $\mathrm{SiO}_{2}$ shell (Fig. 1(d)), Au NPs were sandwiched between the inner ONW template and outer $\mathrm{SiO}_{2}$ shell. The diameter of the $\mathrm{ONW}-\mathrm{Au}-\mathrm{SiO}_{2}$ composite exceeded $300 \mathrm{~nm}$, indicating that the $\mathrm{SiO}_{2}$ shell was dozens of nanometers thick. After calcination, $\mathrm{Au}-\mathrm{mSiO}_{2}$ composite nanotubes were ob-

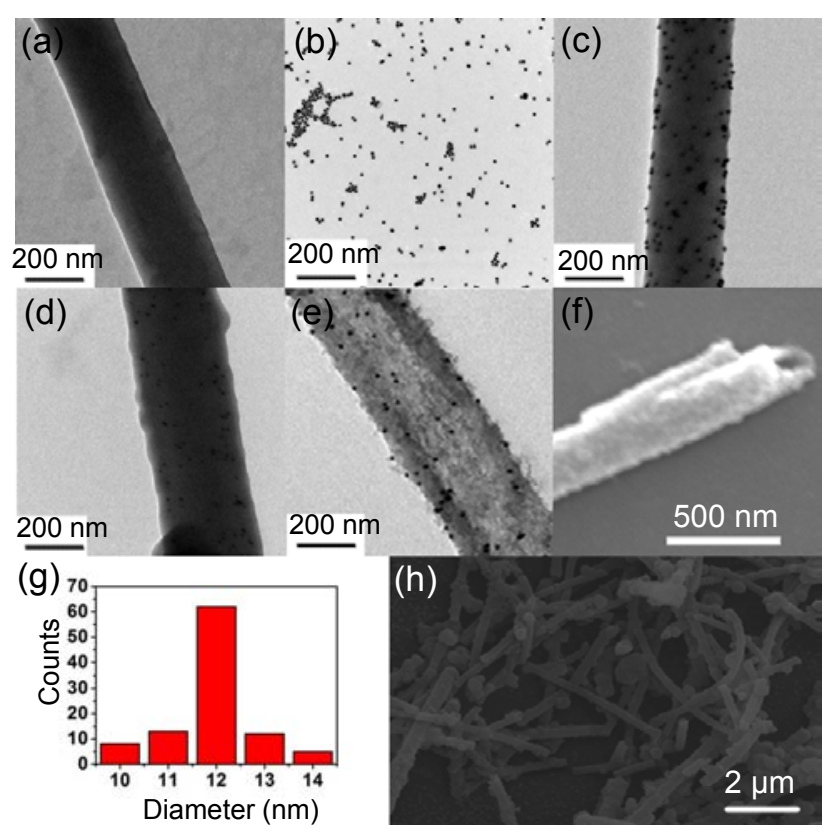

Fig. 1. TEM images of (a) PDDA-modified ONWs, (b) Au NPs with a size of $12 \mathrm{~nm}$, (c) ONW-Au composite, (d) ONW-Au-SiO 2 composite, and (e) $\mathrm{Au}-\mathrm{mSiO}_{2}$ composite nanotubes. (f) $\mathrm{SEM}$ image of open-ended $\mathrm{Au}-\mathrm{mSiO}_{2}$ composite nanotubes, (g) size distribution of $\mathrm{Au} N \mathrm{NS}$ in $\mathrm{Au}-\mathrm{mSiO}_{2}$ composite nanotubes, and (h) SEM image of well-dispersed $\mathrm{Au}-\mathrm{mSiO}_{2}$ composite nanotubes. 

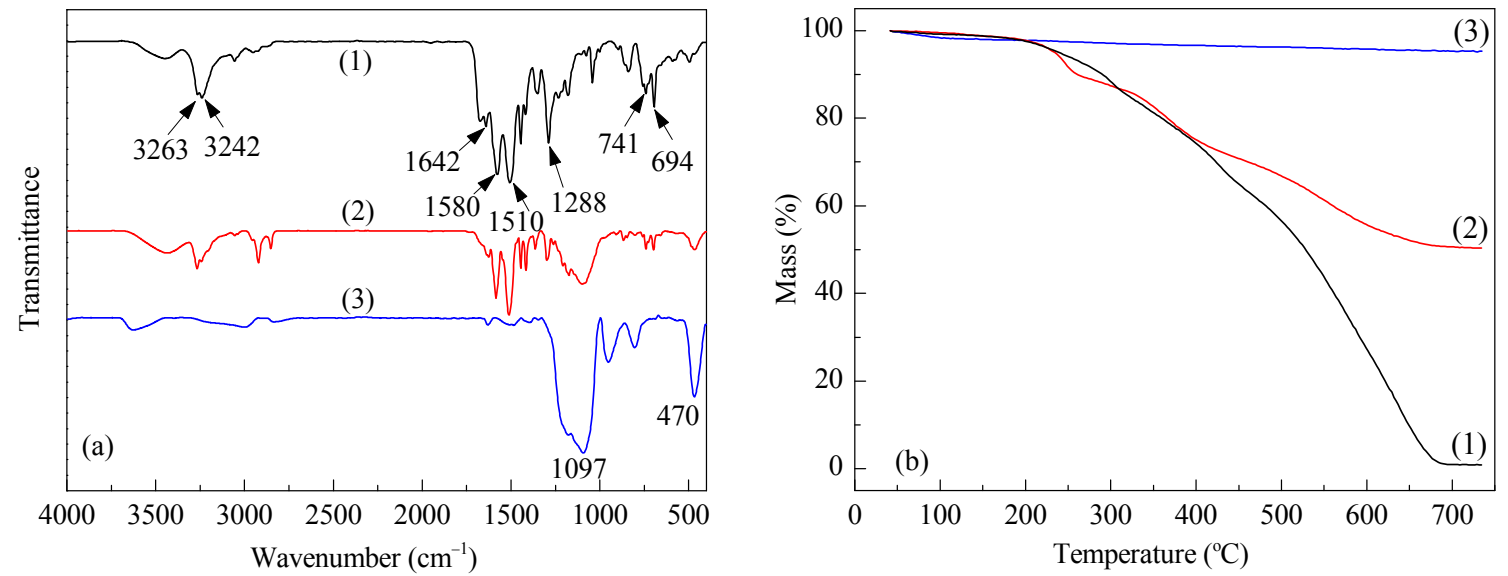

Fig. 2. (a) FTIR spectra and (b) TGA curves for ONWs (1), ONW-Au-SiO 2 composite (2), and $\mathrm{Au}-\mathrm{mSiO}_{2}$ composite nanotubes (3).
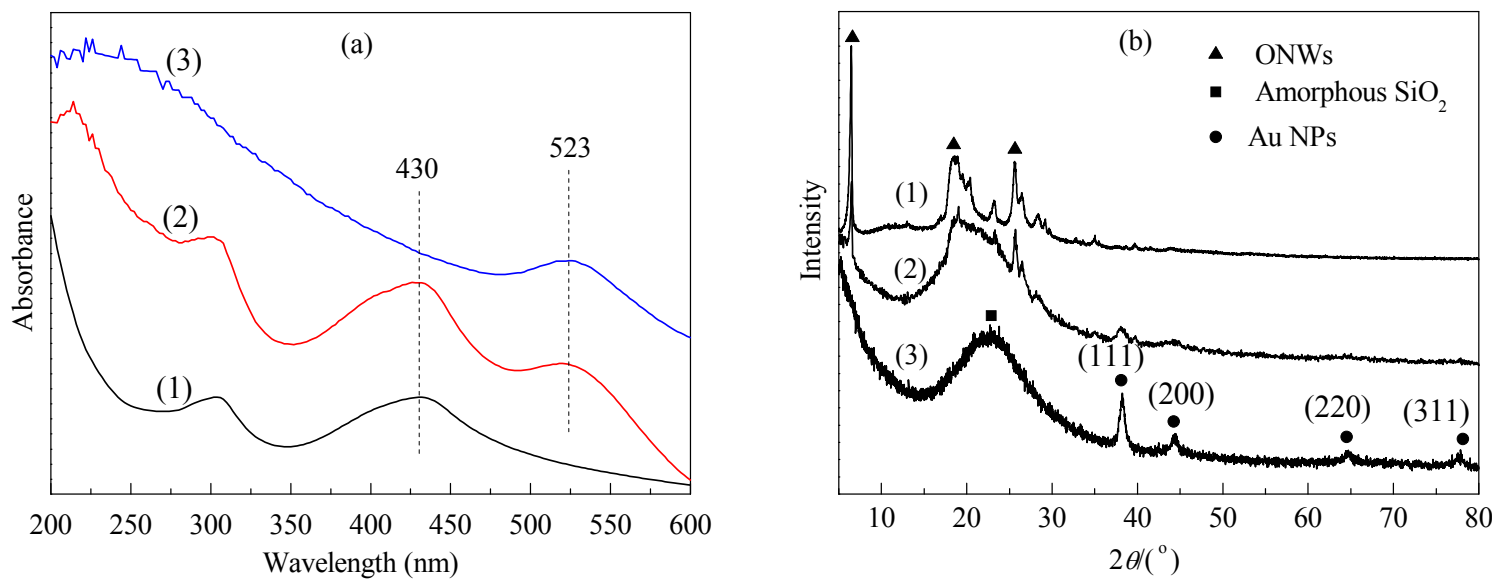

Fig. 3. (a) UV-Vis spectra and (b) XRD patterns obtained for ONWs (1), ONW-Au- $\mathrm{SiO}_{2}$ composite (2), and $\mathrm{Au}-\mathrm{mSiO} \mathrm{O}_{2}$ composite nanotubes (3).

tained (Fig. 1(e)). No free Au NPs were found in the images. In addition, the $\mathrm{Au}$ NPs anchored to the $\mathrm{mSiO}_{2}$ shell were not washed away, confirming the strong interaction between the $\mathrm{Au}$ NPs and $\mathrm{mSiO}_{2}$ shell. The open end of the $\mathrm{Au}-\mathrm{mSiO}_{2}$ composite nanotubes could also be observed (Fig. 1(f)). The uniform size and distribution of the loaded Au NPs were not obviously affected during the synthetic process (Fig. 1(g)), and the composite nanotubes did not aggregate after calcination (Fig. 1(h)).

Unlike the ONWs and $\mathrm{ONW}-\mathrm{Au}-\mathrm{SiO}_{2}$ composite, the $\mathrm{Au}-$ $\mathrm{mSiO}_{2}$ composite nanotubes (Fig. 2(a)) did not exhibit peaks at $3263,3242,1642,1580,1510,1288,741$, and $694 \mathrm{~cm}^{-1}$ in their FTIR spectrum [26]. The disappearance of these characteristic peaks of the ONWs confirms the complete removal of this template by calcination. TGA measurements (Fig. 2(b)) were also consistent with this result because the $\mathrm{Au}-\mathrm{mSiO}_{2}$ composite nanotubes showed negligible mass loss of organic components.

Fig. 3(a) depicts the UV-Vis spectra recorded for the intermediates and final product dispersed in water. The absorptions at 430 and $523 \mathrm{~nm}$ correspond to ONWs and Au NPs with a size of $12 \mathrm{~nm}$, respectively. Compared with the $\mathrm{ONW}-\mathrm{Au}-\mathrm{SiO}_{2} \mathrm{com}-$ posite, the $\mathrm{Au}-\mathrm{mSiO}_{2}$ composite nanotubes showed negligible shift of the 523-nm peak, indicating that the size of the Au NPs barely changed during calcination [22]. This is in accordance with the TEM observations. In the XRD patterns of the samples
(Fig. 3(b)), the broad peak at $20^{\circ}-25^{\circ}$ can be attributed to the amorphous silica shell, and characteristic diffraction peaks for cubic Au (JCPDS No. 04-0784) are observed for the Au- $\mathrm{mSiO}_{2}$ composite nanotubes.

The $\mathrm{N}_{2}$ adsorption-desorption isotherm of the $\mathrm{Au}-\mathrm{mSiO}_{2}$ composite nanotubes is a classical type-IV curve (Fig. 4), indicating that the nanotubes are mesoporous. The most common

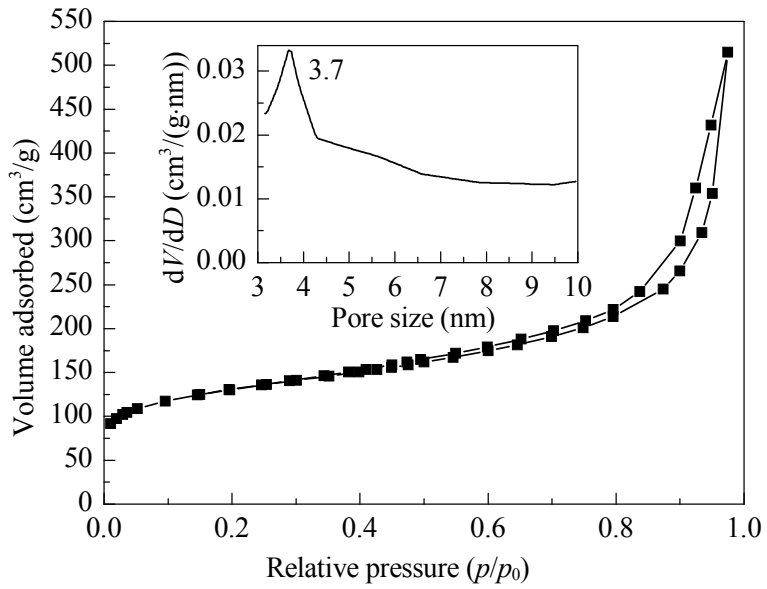

Fig. 4. $\mathrm{N}_{2}$ adsorption-desorption isotherm and pore size distribution curve (inset) of the $\mathrm{Au}-\mathrm{mSiO}_{2}$ composite nanotubes. 


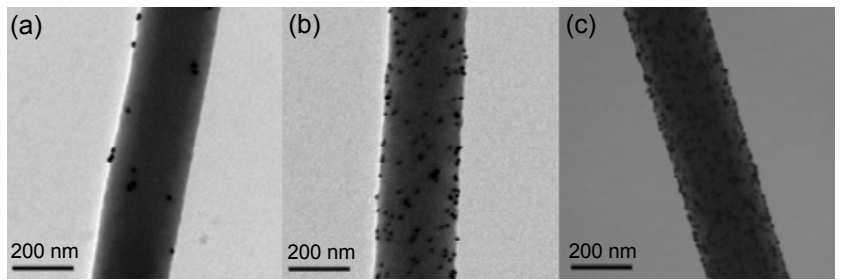

Fig. 5. TEM images of ONW-Au composites with different Au NP loading. The volume of Au NP (12 nm) solution added to a fixed amount of ONWs was: (a) $0.2 \mathrm{~mL}$ ( $\sim 1 \% \mathrm{Au}$ content), (b) $1 \mathrm{~mL}$ ( $\sim 4 \%$ Au content), and (c) $3 \mathrm{~mL}(\sim 8 \%$ Au content). In each case, Au NP solution was injected very slowly into a solution of the PDDA-modified ONWs $(90 \mathrm{mg}$ in $20 \mathrm{~g}$ of water) and stirred for $20 \mathrm{~min}$.

pore size is around $3.7 \mathrm{~nm}$ (inset of Fig. 4), which is large enough for the transportation of molecular reactants. The Brunauer-Emmett-Teller surface area of the $\mathrm{Au}-\mathrm{mSiO}_{2}$ composite nanotubes was $469 \mathrm{~m}^{2} / \mathrm{g}$.

\subsection{Manipulation of the amount and size of loaded Au NPS}

When the amount of ONW template was fixed, the loading of $\mathrm{Au}$ NPs could be controlled by varying the volume of Au NP solution added to the ONWs, as shown in Fig. 5. The uniform dispersity and distribution of Au NPs were well preserved even

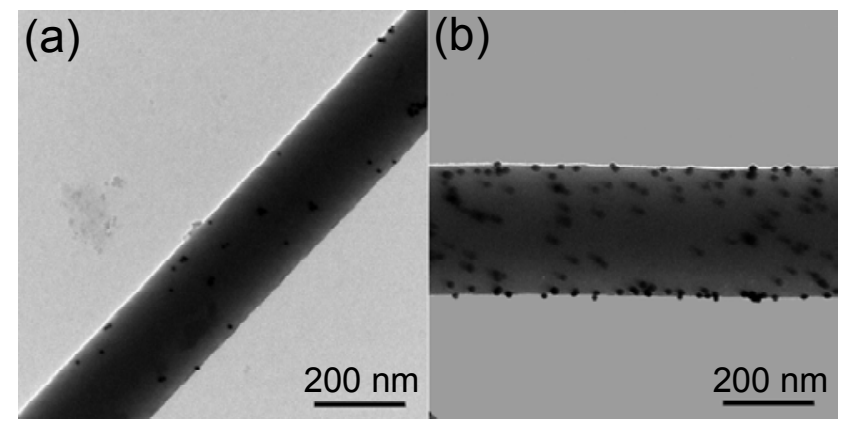

Fig. 6. TEM images of ONW-Au composites containing Au NPs of different size. (a) $5 \mathrm{~nm}(\sim 2 \% \mathrm{Au}$ content); (b) $12 \mathrm{~nm}(\sim 4 \%$ Au content). The volume of Au NP solution added to the ONWs in both cases was 1 $\mathrm{mL}$. Au NP solutions were injected very slowly into solutions of the PDDA-modified ONWs ( $90 \mathrm{mg}$ in $20 \mathrm{~g}$ of water) and stirred for $20 \mathrm{~min}$.

for high-density loading (Fig. 5(c)). In addition, the size of the $\mathrm{Au}$ NPs could also be tuned by using Au NPs of different size (Fig. 6).

\subsection{Catalytic properties of $\mathrm{Au}-\mathrm{mSiO}_{2}$ composite nanotubes}

The reduction of 4-NP by $\mathrm{NaBH}_{4}$ was chosen as a representative reaction to examine the catalytic performance of the
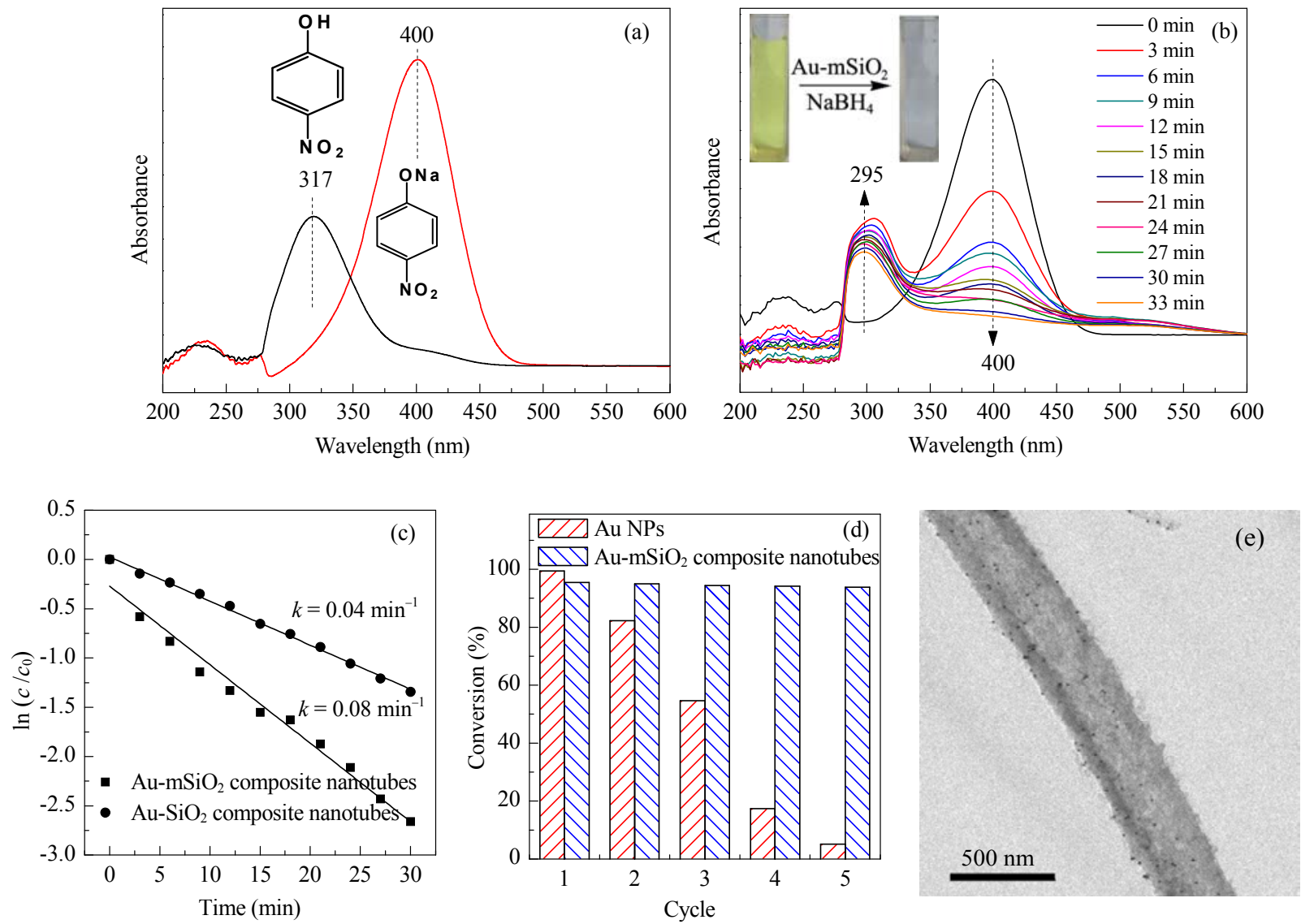

Fig. 7. (a) UV-Vis spectra of 4-NP and 4-nitrophenolate; (b) UV-Vis spectra of the reduction of 4-NP catalyzed by Au-mSiO $\mathrm{O}_{2}$ composite nanotubes; (c) Plots of $\ln \left(c / c_{0}\right)$ versus time using $\mathrm{Au}-\mathrm{SiO}_{2}$ composite nanotubes and $\mathrm{Au}-\mathrm{mSiO}_{2}$ composite nanotubes as the catalyst; (d) The reusability of $\mathrm{Au}-\mathrm{mSiO}{ }_{2}$ composite nanotubes and unprotected Au NPs as catalysts in the reduction of 4-NP; (e) TEM image of a Au-mSiO ${ }_{2}$ composite nanotube after five cycles of catalysis. 
Table 1

Activity of composite catalysts prepared by bottom-up approaches in the reduction of 4-NP.

\begin{tabular}{|c|c|c|c|c|c|c|}
\hline \multirow{2}{*}{ Composite catalyst } & \multirow{2}{*}{$\begin{array}{l}\text { BET surface } \\
\text { area }\left(\mathrm{m}^{2} / \mathrm{g}\right)\end{array}$} & \multicolumn{2}{|c|}{ Loaded Au NPs } & \multirow{2}{*}{$\begin{array}{l}\text { Rate constant } k \\
\left(\mathrm{~min}^{-1}\right)\end{array}$} & \multirow{2}{*}{$\begin{array}{c}\text { Reusability } \\
\text { (cycle) }\end{array}$} & \multirow{2}{*}{ Ref. } \\
\hline & & Size $(\mathrm{nm})$ & Content (\%) & & & \\
\hline $\mathrm{Au} @ \mathrm{SiO}_{2}$ yolk/shell particles & - & $43-104$ & - & $0.10-0.20$ & - & [19] \\
\hline $\mathrm{Fe}_{3} \mathrm{O}_{4} / \mathrm{SiO}_{2} / \mathrm{Au} /$ porous$-\mathrm{SiO}_{2}$ composite colloids & 137 & 15 & - & $0.39-0.82$ & 6 & [20] \\
\hline $\mathrm{Fe}_{3} \mathrm{O}_{4} @ \mathrm{SiO}_{2}-\mathrm{Au} @ \mathrm{mSiO}_{2}$ microspheres & 236 & 12 & $\sim 2.0$ & $0.20-0.35$ & 8 & {$[21]$} \\
\hline $\mathrm{Au} @ \mathrm{SiO}_{2}$ hollow mesoporous nanocomposite spheres & 432 & 12 & $\sim 4.5$ & $0.10-0.15$ & 8 & [22] \\
\hline $\mathrm{Au}-\mathrm{SiO}_{2}$ composite nanotubes & 136 & 12 & $\sim 4.0$ & 0.04 & - & this work \\
\hline $\mathrm{Au}-\mathrm{mSiO}_{2}$ composite nanotubes & 469 & 12 & $\sim 4.0$ & 0.08 & 5 & this work \\
\hline
\end{tabular}

$\mathrm{Au}-\mathrm{mSiO}_{2}$ composite nanotubes with a $\mathrm{Au}$ content of $\sim 4 \%$. The original 4-NP solution exhibited an absorption peak at $317 \mathrm{~nm}$ (Fig. 7(a)). After $\mathrm{NaBH}_{4}$ was added, this absorption band shifted to $400 \mathrm{~nm}$ because of the formation of 4-nitrophenolate. Before adding the catalyst, the color of the organic dye did not fade, even after $24 \mathrm{~h}$; therefore, the addition of catalyst was necessary for the degradation of 4-NP. After $\mathrm{Au}-\mathrm{mSiO}_{2}$ composite nanotubes were added, the mixture was immediately subjected to UV-Vis measurement, which was labeled as the starting point $(t=0)$. UV-Vis measurements of the dispersion were then recorded at intervals of $3 \mathrm{~min}$. The intensity of the absorption peak at $400 \mathrm{~nm}$ gradually decreased as the reaction proceeded (Fig. 7(b)) and a new peak emerged at $295 \mathrm{~nm}$, revealing the conversion of light yellowish 4-NP into colorless 4-aminophenol (4-AP) (inset of Fig. 7(b)). Conversion into 4-AP exceeding $95 \%$ was achieved within $33 \mathrm{~min}$. As previously reported [16] when the concentration of $\mathrm{NaBH}_{4}$ is far higher than that of 4-NP, the reaction rate would be first order with respect to the concentration of 4-NP. As a result, linear plots of $\ln \left(c / c_{0}\right)$ against time were obtained (Fig. 7(c)). The calculated rate constant $k$ was 0.04 and $0.08 \mathrm{~min}^{-1}$ using $\mathrm{Au}-\mathrm{SiO}_{2}$ composite nanotubes (without mesoporous shell, $\mathrm{Au}$ content of $\sim 4 \%$ ) and $\mathrm{Au}-\mathrm{mSiO}_{2}$ composite nanotubes as catalyst, respectively. These values indicate that the mesoporous shell provides a larger surface area and more channels for reactants to diffuse through to the Au NPs, thus increasing catalytic efficiency. To compare the reusability of the $\mathrm{Au}-\mathrm{mSiO}_{2}$ composite nanotubes with unprotected $\mathrm{Au}$ NPs, both catalysts were separated and used in repeated catalytic cycles (Fig. 7(d)). The $\mathrm{Au}-\mathrm{mSiO}_{2}$ composite nanotubes exhibited similar conversion (>95\%) within the same time period for five cycles. In contrast, the catalytic efficiency of bare Au NPs quickly decreased as the cycles proceed because of their agglomeration and loss of catalyst particles. Moreover, the size and content of the $\mathrm{Au} \mathrm{NPs}$ in the $\mathrm{Au}-\mathrm{mSiO}_{2}$ composite nanotubes did not change obviously after five cycles (Fig. 7(e)), excluding leaching and agglomeration of catalyst during reaction.

The activity of previously reported composite catalysts prepared by bottom-up approaches in the reduction of 4-NP is summarized in Table 1 . Overall, the $\mathrm{Au}-\mathrm{mSiO}_{2}$ composite nanotubes showed comparable activity to other spherical-shaped composite catalysts. However, unlike spherical supports, the tubular supports contain open ends and a onedimensional passage. We believe that optimization of these structural features will allow more efficient catalysis of chemical reactions.

\section{Conclusions}

$\mathrm{Au}-\mathrm{mSiO}_{2}$ composite nanotubes were prepared by a bottom-up approach using water-dispersible ONWs as a template. During the synthetic process, a sandwich-like structure of core-Au NP-shell was formed, in which Au NPs were located between the inner ONW template and outer $\mathrm{SiO}_{2}$ shell. As a result, the agglomeration, exfoliation, and grain growth of $\mathrm{Au}$ NPs were restricted. After calcination, $\mathrm{Au}-\mathrm{mSiO}_{2}$ composite nanotubes with $\mathrm{Au}$ NPs anchored to the inner wall were formed. The loading and size of Au NPs could be easily tuned by manipulating the concentration and size of $\mathrm{Au}$ NPs in the dispersion mixed with the ONWs. When the $\mathrm{Au}-\mathrm{mSiO}_{2}$ composite nanotubes were used as catalysts in the reduction of 4-NP, the mesopores, open ends, and one-dimensional passage of the $\mathrm{mSiO}_{2}$ nanotubes jointly facilitated the diffusion of reactants and thus increased catalytic efficiency. These composite catalysts also exhibited good reusability, and their overall activity was comparable to that of previously reported spherical composite catalysts.

\section{References}

[1] Su R, Tiruvalam R, He Q, Dimitratos N, Kesavan L, Hammond C, Lopez-Sanchez J A, Bechstein R, Kiely C J, Hutchings G J, Besenbacher F. ACS Nano, 2012, 6: 6284

[2] Yamada Y, Mizutani M, Nakamura T, Yano K. Chem Mater, 2010, 22: 1695

[3] Zhang P, Shao C L, Li X H, Zhang M Y, Zhang X, Su C Y, Lu N, Wang K X, Liu Y C. Phys Chem Chem Phys, 2013, 15: 10453

[4] Dong Z P, Le X D, Liu Y S, Dong C X, Ma J T.J Mater Chem A, 2014, 2: 18775

[5] Dong Z P, Le X D, Dong C X, Zhang W, Li X L, Ma J T. Appl Catal B, 2015, 162: 372

[6] Arnal P M, Comotti M, Schüth F. Angew Chem Int Ed, 2006, 45: 8224

[7] Cui C H, Yu S H. Acc Chem Res, 2013, 46: 1427

[8] Joo S H, Park J Y, Tsung C K, Yamada Y, Yang P D, Somorjai G A. Nat Mater, 2009, 8: 126

[9] Narayanan R, El-Sayed M A. Langmuir, 2005, 21: 2027

[10] Chen Z, Cui Z M, Niu F, Jiang L, Song W G. Chem Commun, 2010, 46: 6524

[11] John J, Gravel E, Hagège A, Li H Y, Gacoin T, Doris E. Angew Chem Int Ed, 2011, 50: 7533

[12] Xu C, Wang X, Zhu J W. J Phys Chem C, 2008, 112: 19841

[13] Carrettin S, McMorn P, Johnston P, Griffin K, Kiely C J, Hutchings G J. Phys Chem Chem Phys, 2003, 5: 1329 


\section{Graphical Abstract}

Chin. J. Catal., 2015, 36: 1117-1123 doi: 10.1016/S1872-2067(14)60310-7

\section{Bottom-up preparation of gold nanoparticle-mesoporous silica composite nanotubes as a catalyst for the reduction of 4-nitrophenol}

Yongsheng Peng, Wenguang Leng, Bin Dong, Rile Ge, Hongdong Duan *, Yan'an Gao * Qilu University of Technology; Dalian Institute of Chemical Physics, Chinese Academy of Sciences

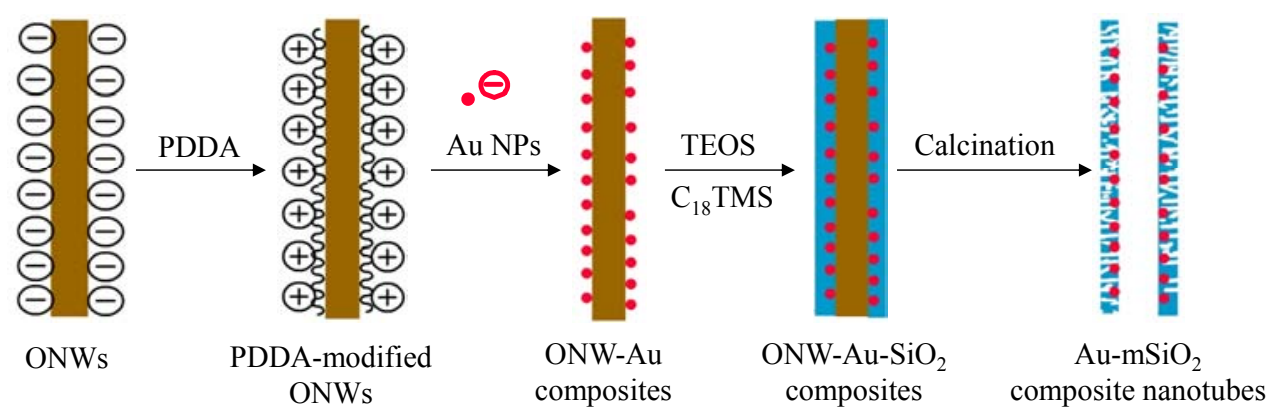

Composite nanotubes consisting of a mesoporous silica shell with gold nanoparticles anchored to their inner wall were prepared by a bottom-up approach. This composite exhibited high efficiency as a catalyst in the reduction of 4-nitrophenol.

[14] Ombaka L M, Ndungu P, Nyamori V O. Catal Today, 2013, 217: 65

[15] Okumura M, Tsubota S, Iwamoto M, Haruta M. Chem Lett, 1998, 27: 315

[16] Wakayama H, Setoyama N, Fukushima Y. Adv Mater, 2003, 15: 742

[17] Junges U, Jacobs W, Voigt-Martin I, Krutzsch B, Schüth F. J Chem Soc, Chem Commun, 1995: 2283

[18] Ma L N, Leng W G, Zhao Y P, Gao Y A, Duan H D. RSC Adv, 2014, 4: 6807

[19] Lee J, Park J C, Song H. Adv Mater, 2008, 20: 1523

[20] Ge J P, Zhang Q, Zhang T R, Yin Y D. Angew Chem Int Ed, 2008, 47:
8924

[21] Deng Y H, Cai Y, Sun Z K, Liu J, Liu C, Wei J, Li W, Liu C, Wang Y, Zhao D Y.J Am Chem Soc, 2010, 132: 8466

[22] Yin Y Y, Chen M, Zhou S X, Wu L M.J Mater Chem, 2012, 22: 11245

[23] Leng W G, Chen M, Zhou S X, Wu L M. Chem Commun, 2013, 49: 7225

[24] Frens G. Nature Phys Sci, 1973, 241: 20

[25] Wang S Y, Wang X, Jiang S P. Phys Chem Chem Phys, 2011, 13: 6883

[26] Stejskal J, Sapurina I, Trchová M, Konyushenko E N, Holler P. Polymer, 2006, 47: 8253

\section{自下而上法制备金-介孔二氧化硅复合纳米管用作还原4-硝基苯酚的催化剂

\author{
彭永胜 ${ }^{\mathrm{a}, \mathrm{b}, \dagger}$, 冷文光 ${ }^{\mathrm{b}, \dagger}$, 董 涁, 格日乐 ${ }^{\mathrm{b}}$, 段洪东 ${ }^{\mathrm{a},{ }^{*}}$, 高艳安 ${ }^{\mathrm{b}, \#}$ \\ 齐鲁工业大学化学与制药工程学院, 山东济南 250353 \\ ${ }^{b}$ 中国科学院大连化学物理研究所, 辽宁大连 116023
}

摘要: 采用自下而上方法制备了金-介孔二氧化硅复合纳米管, 其中金纳米粒子作为催化剂嵌在介孔二氧化硅纳米管管壁内侧. 金纳米颗粒的团聚、脱落和晶粒尺寸生长都可以被有效限制, 而且催化剂负载量和尺寸大小均可实现简单控制. 管壁中的介孔孔 道、纳米管末端开口以及一维中空管道可以协同促进反应物扩散, 从而提高4-硝基苯酚还原反应活性. 循环实验证明这种复合纳 米管催化剂具有良好的可重复使用性,而且在反应过程中未出现金纳米粒子脱落或团聚现象.

关键词: 金; 介孔二氧化硅; 纳米管; 自下而上方法; 催化剂; 4-硝基苯酚还原

收稿日期: 2015-01-07. 接受日期: 2015-02-07. 出版日期: 2015-07-20.

*通讯联系人. 电话: (0531)89631215; 电子信箱: hdduan67@gmail.com

\#通讯联系人. 电话: (0411)84379992; 传真: (0411)84379992; 电子信箱: ygao@dicp.ac.cn

†共同第一作者.

基金来源：国家自然科学基金(21273235, 21303076, 21403214); 中国科学院百人计划.

本文的英文电子版由Elsevier出版社在ScienceDirect上出版(http://www.sciencedirect.com/science/journal/18722067). 